\title{
Earthquake Disaster Management Approach: The Case of Al-Ais, Medina Area in Saudi Arabia
}

\author{
Said Ali El-Quliti' ${ }^{1}$ Tawfiq Bin Saeed Al-Harbi ${ }^{2}$, Mahdi Bin Salem Al-Yami', \\ Ahmed Bin Matar Al-Ghamdi ${ }^{4}$, Mohammed Bin Mattar Al-Shammari ${ }^{5}$ \\ ${ }^{1}$ Department of Industrial Engineering, King Abdulaziz University, Jeddah, KSA \\ ${ }^{2}$ Department of Geophysics at the National Center for Earthquakes and Volcanoes, Saudi Geological Survey, Jeddah, KSA \\ ${ }^{3}$ Natural Studies and Natural Consulting Company, Jeddah, KSA \\ ${ }^{4}$ Fire and Rescue Division of the General Directorate of Civil Defense in Jeddah, Jeddah, KSA \\ ${ }^{5}$ Department of Fire and Rescue Services, Civil Aviation Authority Province of Hail, Jeddah, KSA \\ Email: saidalihassan@yahoo.com,tawfiqalharbi2002@hotmail.com,malyami@outlook.com,algamdi1431@gmail.com, \\ mmalshammari5555@gmail.com
}

How to cite this paper: El-Quliti, S.A., AlHarbi, T.B.S., Al-Yami, M.B.S., Al-Ghamdi, A.B.M. and Al-Shammar, M.B.M. (2016) Earthquake Disaster Management Approach: The Case of Al-Ais, Medina Area in Saudi Arabia. Open Journal of Earthquake Research, 5, 219-235.

http://dx.doi.org/10.4236/ojer.2016.54018

Received: April 20, 2016

Accepted: November 22, 2016

Published: November 25, 2016

Copyright $\odot 2016$ by authors and Scientific Research Publishing Inc. This work is licensed under the Creative Commons Attribution International License (CC BY 4.0).

http://creativecommons.org/licenses/by/4.0/

c) (i) Open Access

\begin{abstract}
The research tackles earthquakes as one of the most dangerous natural disasters. It defines disasters in general, which in turn include earthquakes, how to manage them, stages of their evolution, and their classification among other kinds of disasters such as hurricanes, floods, drought, desertification, etc. Afterwards, it tackles the impacts of disasters on man, buildings and infrastructure. It defines also the codes and laws existing in the Kingdom of Saudi Arabia to confront and treat the impacts of earthquakes in their different stages (before, during and after) and the authorities involved in managing them. Then, it moves to study the case of Al-Ais Earthquake, and identifies the points of deficiency in dealing with such a disaster. Moreover, the research tackles some global experiences in how to handle the situation, reaching to the presentation of a conceptual approach to confront disasters of earthquakes in their various stages.
\end{abstract}

\section{Keywords}

Earthquake, Disaster Management, Al-Ais, Saudi Arabia

\section{Introduction}

Allah made natural disasters, such as earthquakes, volcanoes and others act as a test for man and a reminder for him about the creator's capabilities compared to the limited liabilities of man. Because of natural disasters, the mainland came into existence with its continents and brought out their treasures, and because of them the life ends on 
earth. Man has tried frequently to explain and expect the various natural phenomena and disasters. In this respect, man took steps, as he still thinks and innovates ways that would alleviate their strike and their risks, and even get benefit of such disasters since man realized that it is impossible to prevent their occurrence. Therefore, man took pains to reduce the losses resulting therefrom, either concrete or abstract. Those attempts have contributed in several times to minimizing the size of human and concrete losses.

Natural disasters alone have caused, in the two recent decades of the last century, the death of about three million persons worldwide. In addition, they have negatively impacted on the life of not less than 800 million persons injured and vagrant, and concrete losses amounting to 629 billion dollars in nineteenths only [1].

Earthquakes have been amounted globally in the period from 1975 to 2001 a number of 565 earthquakes, which represents $5.4 \%$ of the number of disasters in the world during this period. Since earthquakes represent the natural disasters that are most frequent and most resulting to losses, this study, which is about the development of mechanisms for managing the disasters resulting from earthquakes in Saudi Arabia and its neighboring countries, a number of which including Egypt, Jordan, Turkey and Iran could be exposed to frequent earthquakes, has been made.

\subsection{Purpose of the Research}

Lack of plans and curricula developed to treat and manage, especially repeated ones such as earthquakes in Saudi Arabia disasters, which exacerbate and increase the impact and damage of these disasters, lack of control and the occurrence of a lot of losses as a result of the impact of indirect resulting from the inefficiency of disaster management.

\subsection{Goal of the Research}

The research aims to develop a plan and a scientific approach to face the disasters resulting from earthquakes in Saudi Arabia, highlight the importance of the role of architectural plans in the decision-making process, and develop relevant strategies to limit the damages and losses resulting from the disasters of earthquakes. This is through studying and analyzing some of the local and international experiences, in order to reduce the material and human losses caused by earthquakes.

\subsection{Methodology of the Search}

The approach used in this research consists of three stages as follows:

- The first phase deals with the general definitions and concepts for the disaster, and disaster management and earthquakes, features and characteristics of these disasters.

- The second phase shall provide samples for disaster management in the Kingdom of Saudi Arabia and the developed world.

- The third phase identifies proposed approach to disaster management from earthquakes in three stages, before, during and after the disaster, through the assessment 
of past experiences.

\subsection{Concepts and Definition of a Disaster}

The concepts of the various elements of a disaster and the full definition of the problem, which is the subject matter of the study, are brought up as they play a key role in the disaster management. These definitions are reviewed as follows:

\subsubsection{Disaster}

It is an incident determined temporally and spatially, and making an entire community or a part of one be exposed to severe material risks and losses that could be caused to the individuals of such community, and which may affects the social structure by confusing its life and suspending the provision of the requirements essential for its continuity [2]. While a disaster is defined by R. Green as it is the sudden change having intense impacts, which takes place because of changes related in forces that lead to the collapse of the balance [3].

The other definition is a system for confronting the emergency situations, and planning to deal with cases that cannot be avoided, when or before they occur, in order to control the results.

There is another concept defining the crises management as it is a special administrative process that would produce a strategic response to crisis situations through a set of pre-selected and specially-trained administrators in order to reduce losses to the minimum.

While the international definition provided by the International Civil Defense Organization stipulates that "it is a big incident resulting in huge losses of life and property, which may be natural disasters made by nature (floods-earthquakes-accidentsetc...), and may be technical disasters made by man, either voluntarily (intentionally) or involuntarily (negligence)". This definition also explains that a disaster, which confrontation requires the aid of the home or at the international level if its confrontation surpasses the capabilities of the homeland [4].

\subsubsection{Disaster Management}

The disaster management can be defined as all of the means, procedures and activities carried out in the three stages of a disaster (before, during and after) (Figure 1), which aims to achieve the following:

- To prevent a disaster whenever possible.

- To face a disaster efficiently and effectively.

- To reduce losses to the minimum.

- To minimize the negative effects on the surrounding environment.

- To remove the psychological effects of the disaster on citizens.

- To analyze and get ready for incidents in the three stages of a disaster, and to improve and develop the self-capacities for confronting disasters.

\subsubsection{Disaster Alert}

It alerts inhabitants by all available means to ensure that most of individuals are informed 


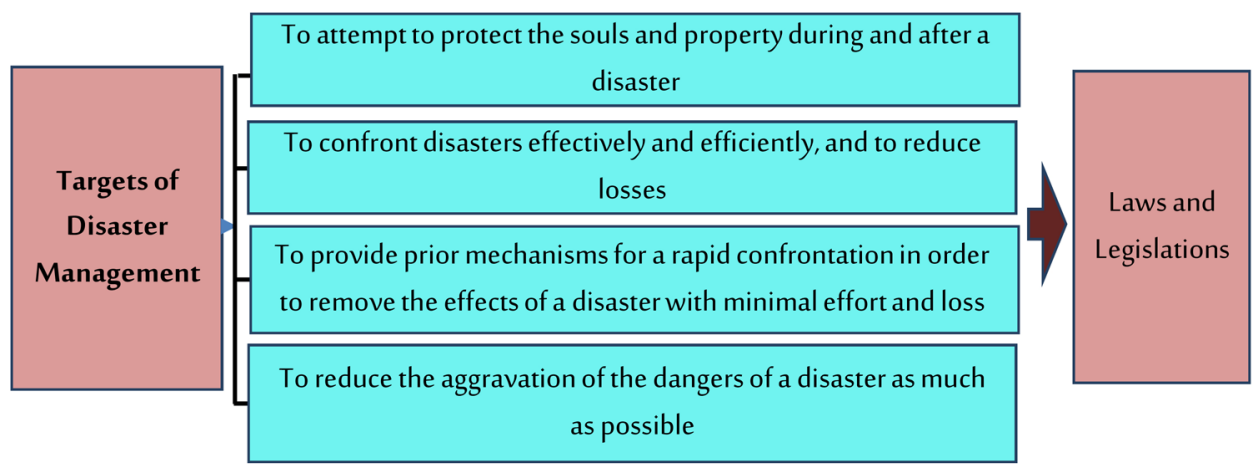

Figure 1. Targets of disaster management.

with the existence or removal of the various sources of disasters, in order to take the necessary measures to protect individuals and property.

\subsubsection{Disaster Relief}

It is defined as the provision of food, clothing, shelter, treatment, and all the requirements for those affected by disasters [5].

\section{Characteristics, Stages and Features of Disasters}

\subsection{Characteristics of Disasters}

Allah Barton has developed a table classifying the characteristics of disasters and has chosen to them five dimensions [6], which are:

1) Scope of Impact:

It represents the scope or the circle containing those affected by a disaster, and whenever the geographic scope is less, the less the number of people affected and the size of the disaster will be reduced.

2) Surprise:

Whenever an incident is unexpected temporally and spatially, its impact will be greater and heavier, while the impact of preparations will be less, and vice versa.

3) Center of Disaster:

It constitutes the center of disaster or its start point, and has a great role in influencing, as the larger the regions have a population density and urban density, the greater the impacts and losses are, and vice versa.

4) Duration of Impact:

It illustrates the time period since the beginning of a disaster until the impact breakpoint. It also plays a key role in the size of the losses, as the more the time of the disaster increases, the more their devastating impact increases. A disaster may take seconds such as earthquakes, minutes such as storms, or hours such as floods or more.

5) Impacts resulted from Disaster:

It reflects the impacts of a disaster (that are resulted therefrom), as they may be more devastating than the disaster itself, such as the spread of epidemics and diseases, the suspension of services and others. 


\subsection{Features of Disaster}

They are the criteria and indicators, by which the impact of disaster can be measured, which are:

1) Repetition Rate:

It expresses how often a disaster takes place during twenty years, and the more the repetition rate increases, the more its impact increases, and the more the importance of the exact planning appears to confront it.

2) Impact Extent:

It reflects the size of the losses and injuries of lives and property, and the costs required to return situation to its state before the disaster. There is a direct correlation among the scientific capability of expectation, the increase of efficiency of the disaster management, and the control of such disaster.

\subsection{Disaster Management Stages}

Disaster management stages can be divided into three stages, each of which has a great importance in reducing the impact resulted therefrom. Figure 2 illustrates disaster management stages, which are:

1) Pre-Disaster Stage:

It is concerned with the information collection, the definition of disaster, its characteristics and location, the probability of its occurrence, the method of preparation and training, and the development of plans and alternative plans to encounter it.

2) During-Disaster Stage (Period of Disaster Occurrence):

In this stage, it is dealt with the disaster according to the preparations and training made in the previous stage. It is also dealt with new developments, and proposed plans are applied.

3) Post-Disaster Stage:

It is the stage in which the disaster-confronting plan is completed, the impacts resulted there from are contained and treated, the performance during this disaster is evaluated, plans are developed, and new developments caused thereby, new technology developments and the experiences of others are added.

\section{Earthquakes as a Source of Disasters in Saudi Arabia and Arab Countries}

\subsection{Definition of Earthquake}

An earthquake is a natural phenomenon occurring suddenly and rapidly as a result of

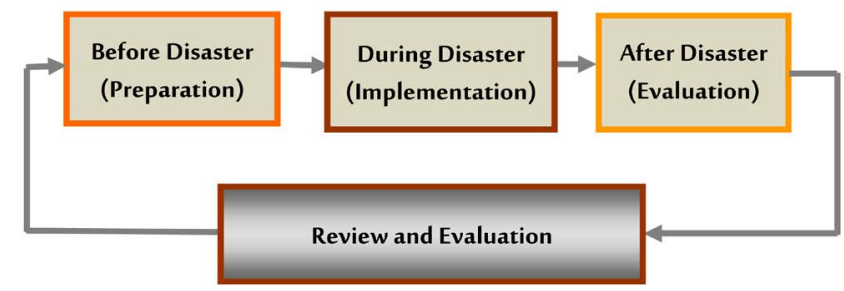

Figure 2. Disaster management stages applied to all disasters. 
the outburst of the energy concealed in rocks, and the spread of seismic waves in those rocks.

There is another definition identifying an earthquake as a tremor taking place suddenly due to underground disorders, either in the crust itself or in the formation underlying the crust, and such tremor lasts for few seconds.

In another definition, it is a sudden outburst of the energy hidden in the subsoil over time in the form of kinetic energy carried by seismic waves upon their occurrence, which are spread in all directions from the center of earthquake [7].

\subsection{Causes of Earthquake}

Earthquake takes place due to the Elastic Rebound Theory, which is a result of the continuous accumulation and storage of energy along a weak line in the crust of the earth. Thus, intense pressure are generated, which are hard for rocks to resist, leading to the breakdown of rocks along the fault into two parts, each of which recovers its original shape through the elastic rebound as illustrated in Figure 3. Then, the energy erupts in the form of seismic waves and tremors. Earthquakes may take place because of man as a result of the construction of dams and artificial lakes, or nuclear explosions.

\section{Classification of Earthquakes According to Their Causes}

- Earthquakes resulted from the relative movement of tectonic plates.

- Earthquakes caused by the faults resulted from volcanoes.

- Earthquakes caused by the collapse of the ceiling of caves and giant caves.

- Earthquakes resulted from the human activity (explosions, filling and emptying dams, nuclear explosions).

- Industrial lakes-(injecting liquids into some oil exploration and extraction).

There are a large number of earthquakes that occur in the Arab region in general and Saudi Arabia in particular, because of the tectonic plates, as shown in Figure 4. However, there are also other causes of earthquakes, and in general the stock of earthquakes and their Pictures around the world show that the earthquake may occur in any area, as in Figure 5, and at the confluence of tectonic plates also.

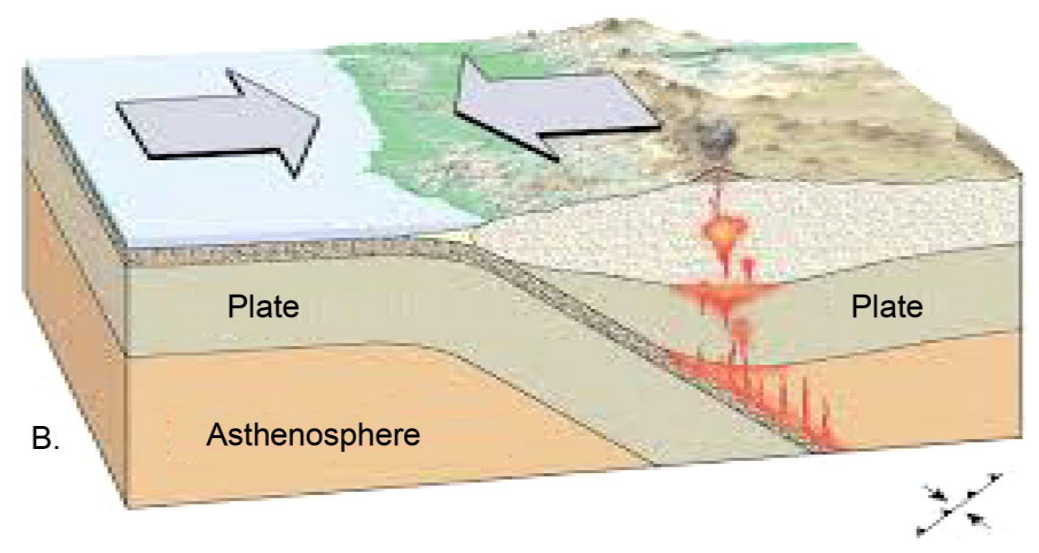

Figure 3. Various forms of movement. 

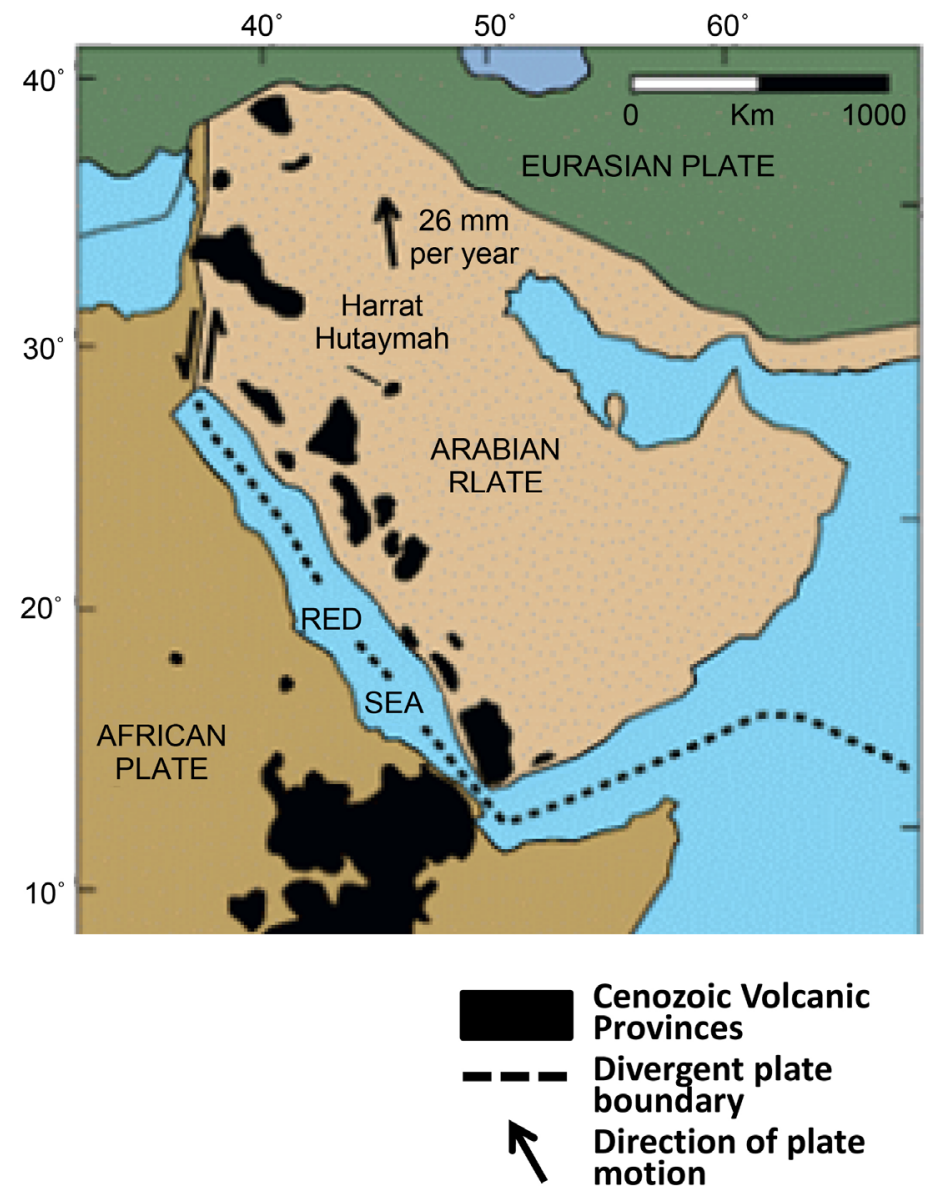

Figure 4. Earthquakes that occur in the Arab region and Saudi Arabia.

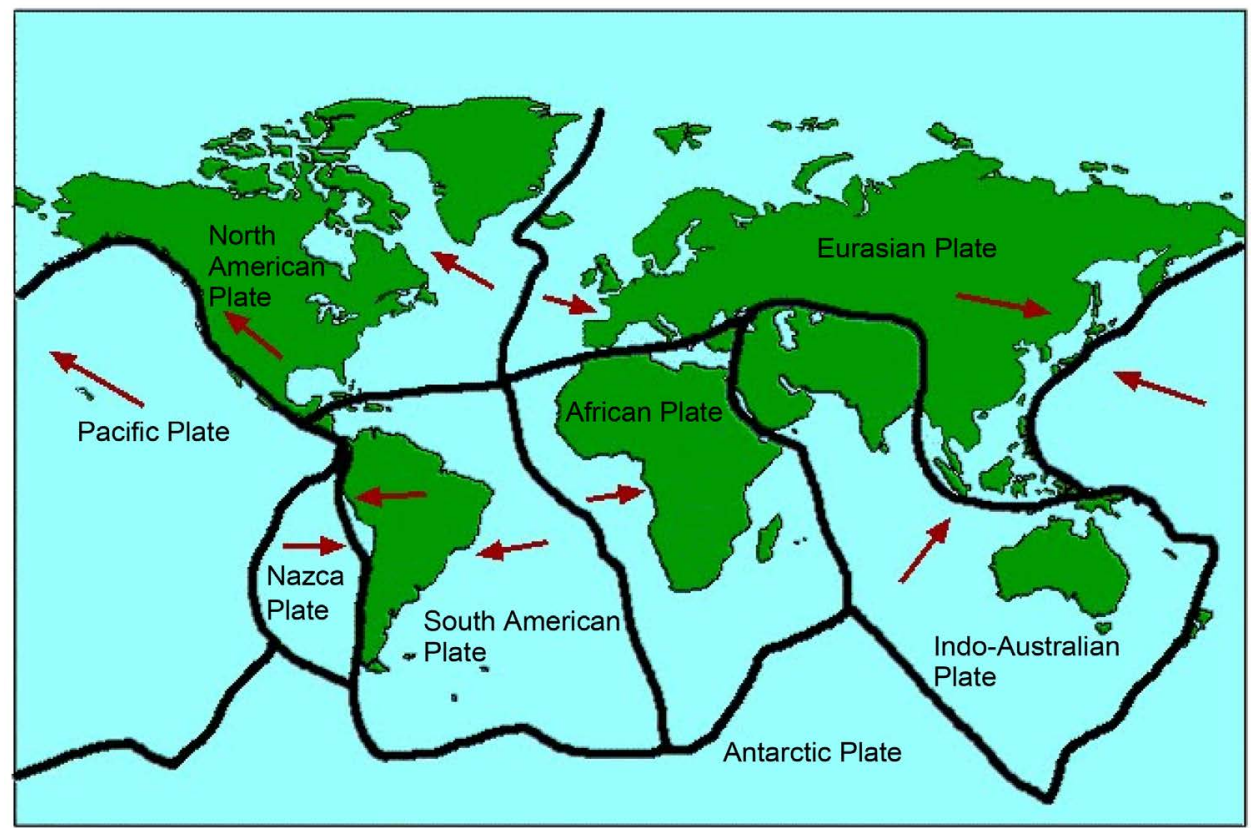

Figure 5. Tectonic plates around the world. 


\subsection{Seismic Standards}

There are two major factors to classify earthquakes:

1) The Modified Mercalli Intensity Scale:

It is one of the scales depending on the knowledge of the damage caused by the earthquake. The Modified Mercalli Intensity Scale is divided into 12 classifications, Table 1. It is obvious that it is an inaccurate scale, and various elements may interfere into its impacts. Its grade is reviewed as follows [8].

2) Richter Scale:

It explains the size of an earthquakes, and it is an open scale, the values of which are determined on the basis of the decimal logarithm of the great amplitude measured as a part per thousand of a millimeter at a distance of $100 \mathrm{~km}$ from the epicenter of the earthquake, and its values are amounted to 9 Richter as stated in Table 2 [9].

\subsection{Different Effects of Earthquakes}

The earthquakes shall have effects on all districts and the components of the earth as follows:

\subsubsection{Earthquake Effects on Human Lives}

Earthquakes shall be deemed as one of the most natural disasters that claimed the lives of a large number of victims and inured on the earth as the number of victims in the past two decades have been three million killed people and 550 injured while in the Arab region, the number of victims in the 1992 Cairo earthquake has been only 561 killed and 1500 injured approximately and the number of killed by the earthquake of Boumerdes Algeria 2003 has been 2266 killed and 10,261 injured. The 1980 Chlef Algeria earthquake has led to the death of 5000 persons and the Agadir Morocco earthquake has led to the death of 12 thousand out of 50 thousand inhabitants in the city. In the worldwide the victims of one earthquake in china in 1976 has been 655 thousand killed

Table 1. Classification of earthquakes.

\begin{tabular}{cr}
\hline Intensity & Description \\
\hline 1 & None feels he earthquake except a few number of people in certain conditions. \\
2 & It is felt by a few people at rest, and light hanging things oscillate. \\
3 & It is felt by people inside their houses, and parked cars shake. \\
4 & Sleepers wake up, parked cars clash, and windows collide. \\
5 & It is felt by all people, who become panicked, and furniture moves. \\
6 & House dwellers rush to outside, and it is felt by people in moving cars. \\
7 & Poorly-constructed houses totter, and water change its passes in basins. \\
8 & Well-constructed buildings falter, the earth is cracked, and underground water pipes smash. \\
9 & Water comes out of riverbeds, and only a few buildings remain. \\
10 & The underground water explodes, and the earth widely cracks. \\
12 & Mass destruction happens, natural landmarks change, and things fly in the air. \\
\hline
\end{tabular}


Table 2. Richter scale grades impacts and horizontal velocity.

\begin{tabular}{|c|c|c|}
\hline Earthquake Effects & $\begin{array}{l}\text { Horizontal } \\
\text { Velocity } \\
\text { Cm/sec. }\end{array}$ & $\begin{array}{c}\text { Grades by } \\
\text { Richter Scale }\end{array}$ \\
\hline $\begin{array}{l}\text { Nobody feels the earthquake except some people under very special } \\
\text { circumstances. }\end{array}$ & - & 3 \\
\hline $\begin{array}{l}\text { It is felt only by some people, and the things that are freely hanging } \\
\text { tremble. }\end{array}$ & $2-3$ & 3.5 \\
\hline $\begin{array}{l}\text { It is clearly felt in houses as it causes shakings such as the ones } \\
\text { caused by the metro. }\end{array}$ & $4-7$ & 4 \\
\hline It is felt as if a truck collides with a building, and vehicles shake obviously. & $7-15$ & 4.5 \\
\hline $\begin{array}{l}\text { Wall portraits fall, unbalanced things are turned over, and the pendulum } \\
\text { of watches stops. }\end{array}$ & $15-30$ & 5 \\
\hline $\begin{array}{l}\text { It is felt by everyone, heavy pieces of furniture move, and chimneys and } \\
\text { weak buildings crack. }\end{array}$ & $30-70$ & 5.5 \\
\hline Cracking is remarkable in poor-concrete buildings and loadbearing walls. & $70-150$ & 6.0 \\
\hline $\begin{array}{l}\text { Cracking is simple in earthquake-resistant installations. There is a big } \\
\text { crack in buildings having loadbearing walls. Buildings separate from } \\
\text { columns and beams, and some of them move out. Statues, minarets, } \\
\text { chimneys and fences fall. Heavy pieces of furniture are turned over, } \\
\text { and the level of well water changes. }\end{array}$ & $150-300$ & 6.5 \\
\hline $\begin{array}{l}\text { Cracking is obvious in earthquake resistant installations, concrete } \\
\text { installations. In addition, some buildings separate from their } \\
\text { bases, and the soil splits clearly. }\end{array}$ & $300-700$ & 7 \\
\hline $\begin{array}{l}\text { Most buildings having loadbearing walls are destroyed, and some concrete } \\
\text { installations and their bases are ruined. The earth is split apart into big and } \\
\text { serious cracks, and railways are bent. Sides of rivers and canals slide, and } \\
\text { the sand soil and the silt move. }\end{array}$ & $700-1500$ & 7.5 \\
\hline $\begin{array}{l}\text { Most buildings having loadbearing walls collapse, and concrete buildings } \\
\text { are destroyed. Bridges fall, making in the earth breaks swallowing people } \\
\text { and vehicles. Water and sewage networks collapse altogether. }\end{array}$ & $1500-3000$ & 8 \\
\hline $\begin{array}{l}\text { The destruction is mass, as seismic waves can be seen on the ground } \\
\text { obviously, and heavy objects fly in the air. }\end{array}$ & $300-600$ & 8.5 \\
\hline
\end{tabular}

and has been 50 thousand killed in the 1990 Iran earthquake in addition to the severe psychological effects and the horror incurred by millions of people during and after the earthquake for a long time [10].

\subsubsection{Economic Effects of Earthquakes}

The resulting losses from the earthquakes shall be amounted by billions in addition to the destruction of large proportion of the infrastructure according to the severity and duration of the earthquake.

\subsubsection{Earthquake Effects on the Buildings}

The buildings shall represent the most effected element by earthquakes as it shall start with the appearance of superficial simple cracks and severe cracks though either struc- 
tural building which is less affected by load-bearing walls. The damage shall reach up to the full depreciation of buildings in the region, located in the center of the earthquake.

\section{Analytical Study of the Experiences of Disasters Management (Earthquakes)}

\subsection{Al-Ais Earthquake (May 2009)}

Al-Ais (Figure 6) governorate shall be located in the northwestern part of Yanbu which space is amounted to $2863 \mathrm{~km}^{2}$, representing $15.86 \%$ of the space of Yanbu. It is located in the northeast of Yanbu and $150 \mathrm{~km}$ from trading between Quraysh to Syria-ancientand called in the way of Ma'rib Petraa. It is bounded by the city of Amlag with about $120 \mathrm{~km}$ and from the east with Medina at the distance of $240 \mathrm{~km}$ and from the north with approximately $200 \mathrm{~km}$. such geographical location shall be distinguished for being located at the crossroads of ancient and modern groups and rising from the sea service with approximately $1200 \mathrm{~m}$. the climate shall be hot in the summer and cold in the winter.

The number of population shall be 12,812 people. It shall be ranked at the second level in terms of the number of populations at the level of Yanbu and shall be surrounded by mountains from the most destinations. It shall be intertwined in the mountains with the steep slopes with a number of valleys that form an important tributary of the valley of (Al-Ais) and represent vast expanse of planted plains with wheat upon raining.

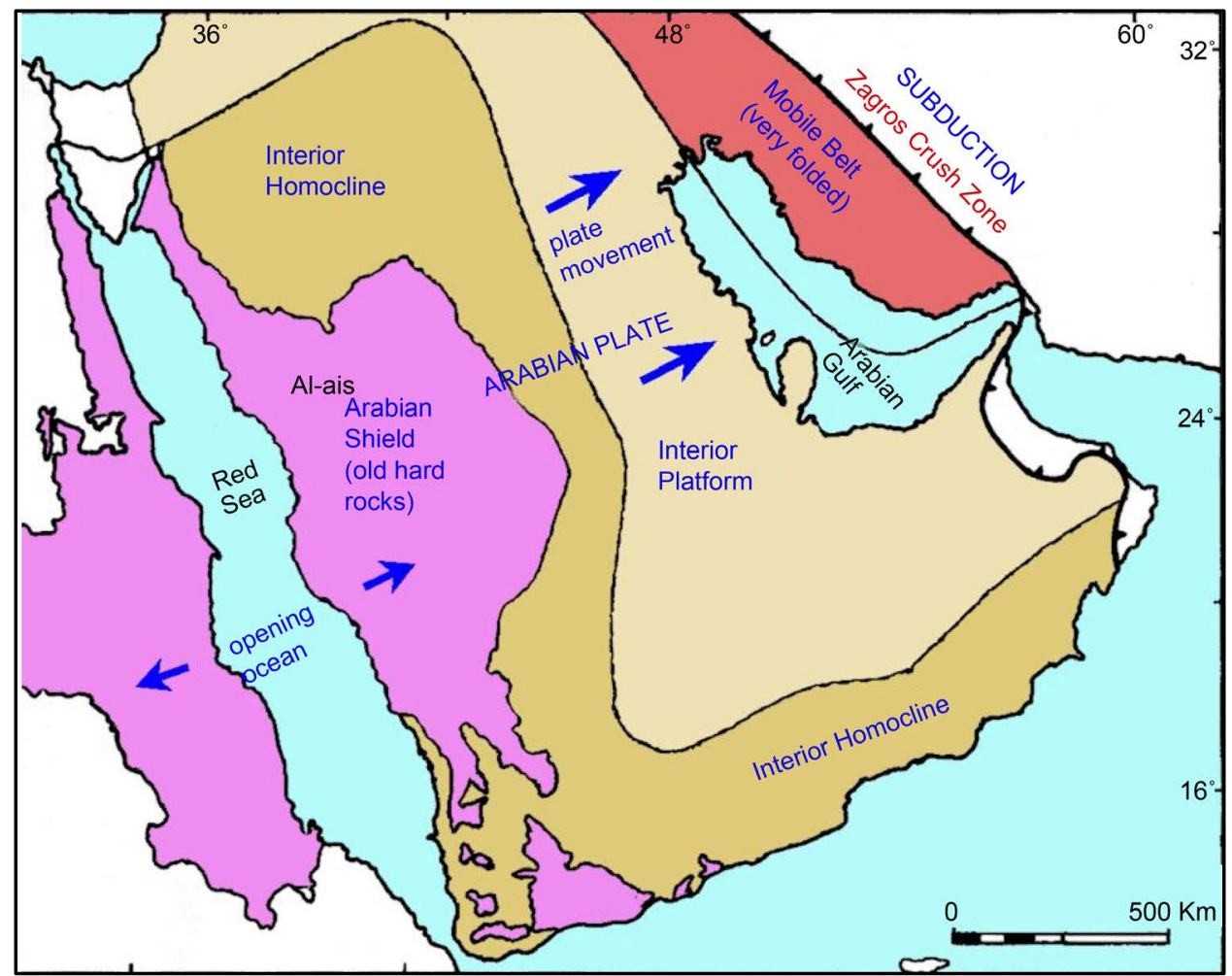

Figure 6. Map of Saudi Arabia-the Arabian Shield and Ais area. 
Many of the mountains that form Al-Ais: Abu Elketta, Tora, Radwh, Alagrad, Hisham, Al Sala, Al Mokannaa Alracib, Al Habshi and these mountains are permeated by several valleys, including Toraa, Arafa, Al Ran, Hegag, Allahyan, Al Haver, Al Safeha, Baya, Al Ramas valley and otherwise.

A water tank for the area of Al Harra shall be formed and the water tank of the region has been hit. It has the length of $60 \mathrm{~km}$ approximately from the east to the west and approximately $25 \mathrm{~km}$ from the north to the south. It has been planted after the heavy rain in the winter and there are also known for their dormant volcanoes as in Halian [11].

$\mathrm{Al}$-Ais City is located within the active tectonic environment whereas it has been witnessed by large earthquakes in historic and useful periods. Recently, in May 2009, Al-Ais city has unveiled a series of earthquakes of 5.7 degrees on the Richter scale due to the volcanic activity in Heart Al Shaka (Lunayyir) as shown in Figure 7 and Figure 8 as more than 3000 earthquakes have been occurred during the month including 30 ones that reached to the degree of 3.7 on the Richter scale while the citizens have viewed only 15 shake thereof.

The authorities have begun the forced evictions on May 19, 2009 for the people around $20 \mathrm{~km}$ around $\mathrm{Al}$ Ais Volcano Center and the area is free of the populations till the date of June 27, 2009 for an indefinite period due to the continuity of the earthquake and at the rate of 4-5 daily shakes which power ranges between 4-3-5 degrees on the Richter scale. The nick name shall be deemed as located within the existing areas of the earthquake belt in the region [12].

Figure 9 indicates the status of $\mathrm{Al}$ Ais province and the surrounding area thereto for the map of the Kingdom of Saudi Arabia and schedule 1 shall indicate the significant places in the volcanic eruptions (lanes) in the nick name province and the surrounding area thereto Nos. 3, 4 and the cracks shall be appeared in the ground as a result of the earthquakes in Lunayyir ( $\mathrm{Al}$ Shaqa) explosion and other nearby places to Al-Ais Province. The figure represents the most important destinations of the volcanic eruptions (lanes) in Nick name and the surrounding area thereto [13].

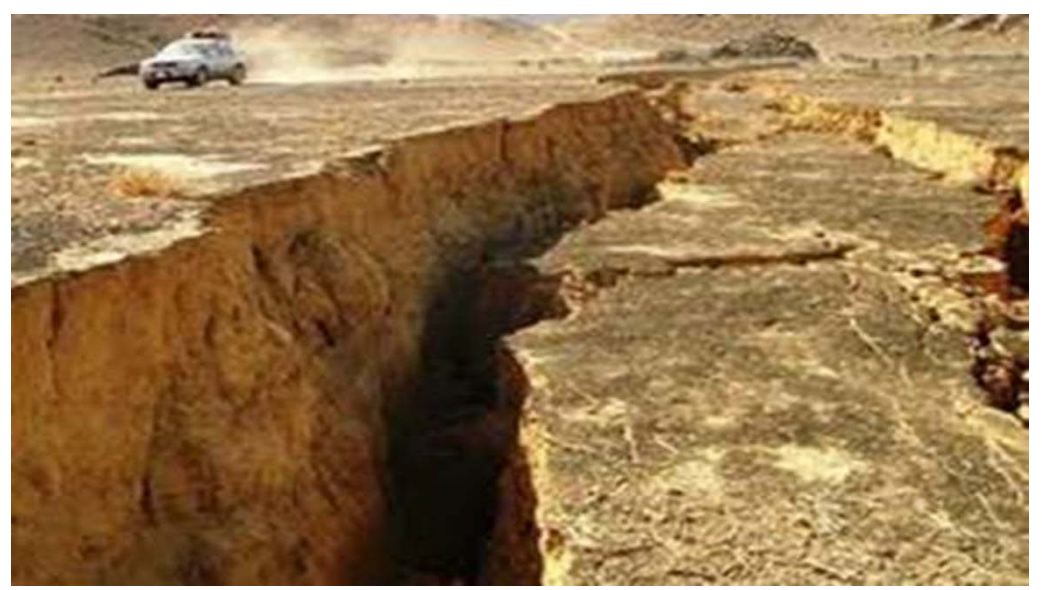

Figure 7. Cracks in the ground as a result of earthquakes in Lunayyir (Al-Shaqa) eruption. 


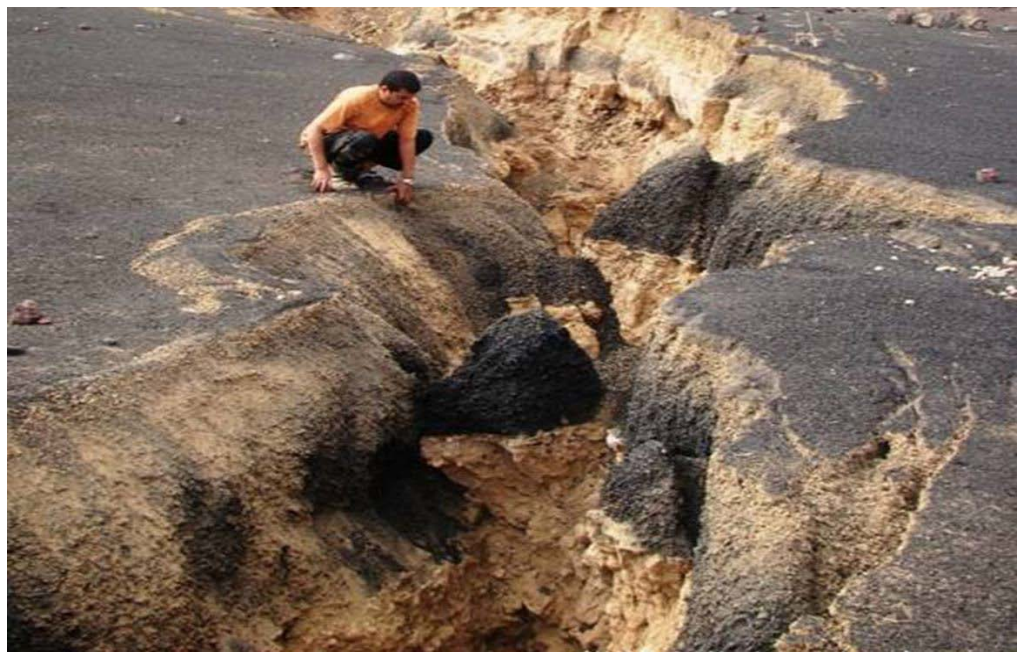

Figure 8. Cracks in the ground as a result of earthquakes in Alais area.

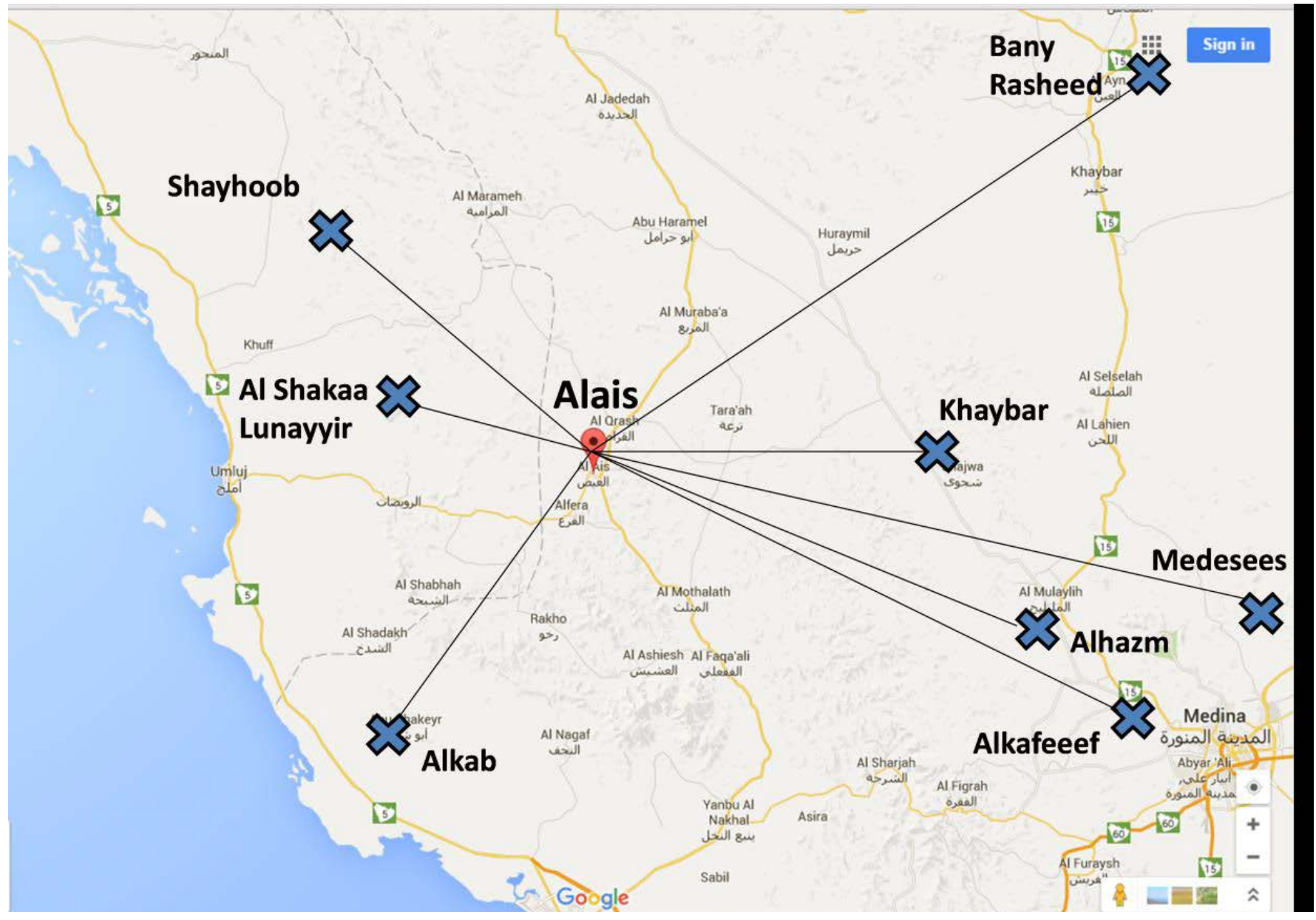

Figure 9. The most important volcanic eruption places (Harrat) in Alais and surrounding area.

\subsection{Al-Ais Earthquake Disaster Management Process in 2009}

Use of regulation in the status of the event as in Figure 10. 


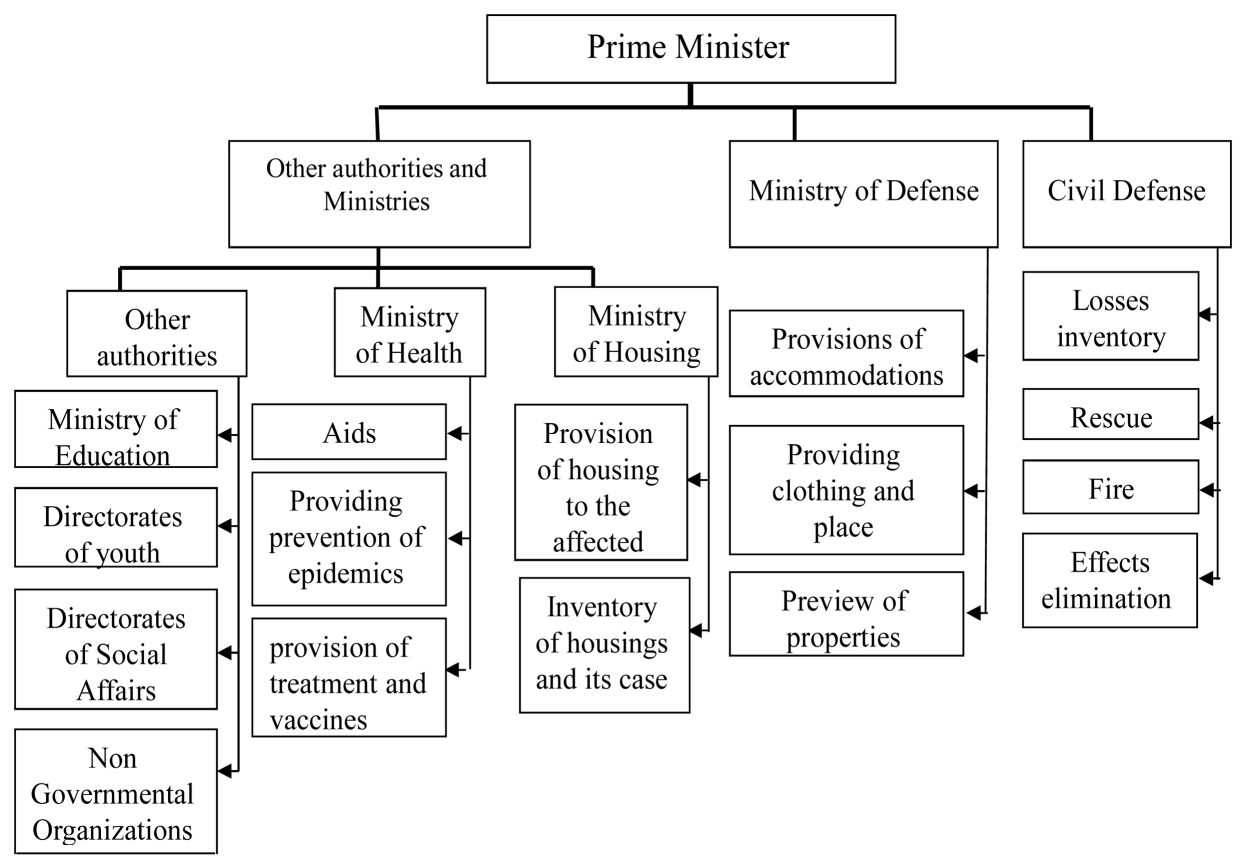

Figure 10. Management plan and authorities in Al-Ais earthquake in 2009.

Due to the lack of unwillingness and the surprise of the event, the event management has been less than the required level as if the popular participation has not the effective and entrusted role thereto as of not being qualified for the event management, however, once the event has occurred, several axes foe movement have been determined:

- Forming the operations room, operating around 24 hours for receiving the communications and to speedily evacuate the dilapidated buildings.

- Making a quick inventory of the areas, affected by the earthquake and assessment of the size of losses.

- The speed of implementing the emergent accommodation works for the effected from the earthquakes so as to accommodate all families along with the services of the facilities and subsistence as acceptable on the basis of being temporary phase.

- Considering the subsidies or compensations to be submitted to the effected.

- Developing a timetable for the transfer of the affected families by the emergent accommodation of the housing units.

The incident has been as a notification for starting the development of plans and preparations for any emergent accident and the competent authorities have taken the following procedures:

- The announcement of emergency cases in all the provinces apparatus, authorities and the facilities of different services.

- Raising the willingness degree in all the central hospitals and health units along with the provision of ambulances with sufficient numbers and readiness for immediately directing to the place of communication.

- Transferring the central rescue devices immediately to the incidents sites and focusing on the popular areas. 
- Forming a supreme committee for housing and transferring the affected families which became homeless to the prefabricated and prepared housings.

- Forming engineering groups for previewing the dilapidated properties and evacuating what is subjected to collapse. The university professors and armed forces engineers as well as the Ministry of Construction have been taken advantage thereof.

- Developing a plan for the fast completion of the number of housings, built by the province and providing them with the facilities for the purpose of the speed of housing of all affected families, that live in the tents.

- Issuing decisions for the commissioning by business sector companies for removing the collapsed houses or reducing the floors to be removed or otherwise conducting the restoration works.

- Conducting the works of preventive health works by the Directorates of Health such as spraying the pesticides in the accommodation areas along with the vaccination works and health survey.

- Opening the youth centers by the Directorates of Youth and Sports at the provincial levels for setting up the tents in the form of aggregated camps.

\section{Proposed Approach for Earthquake Disaster Management}

The disasters management, resulting from the earthquakes shall play an effective role in reducing the damages and losses, resulting from the earthquakes and Figure 11 shall indicate the proposed approach for managing the resulting disasters from the earthquakes.

First: pre-disaster phase:

In this phase, all data and information of the resulting disaster for the earthquakes

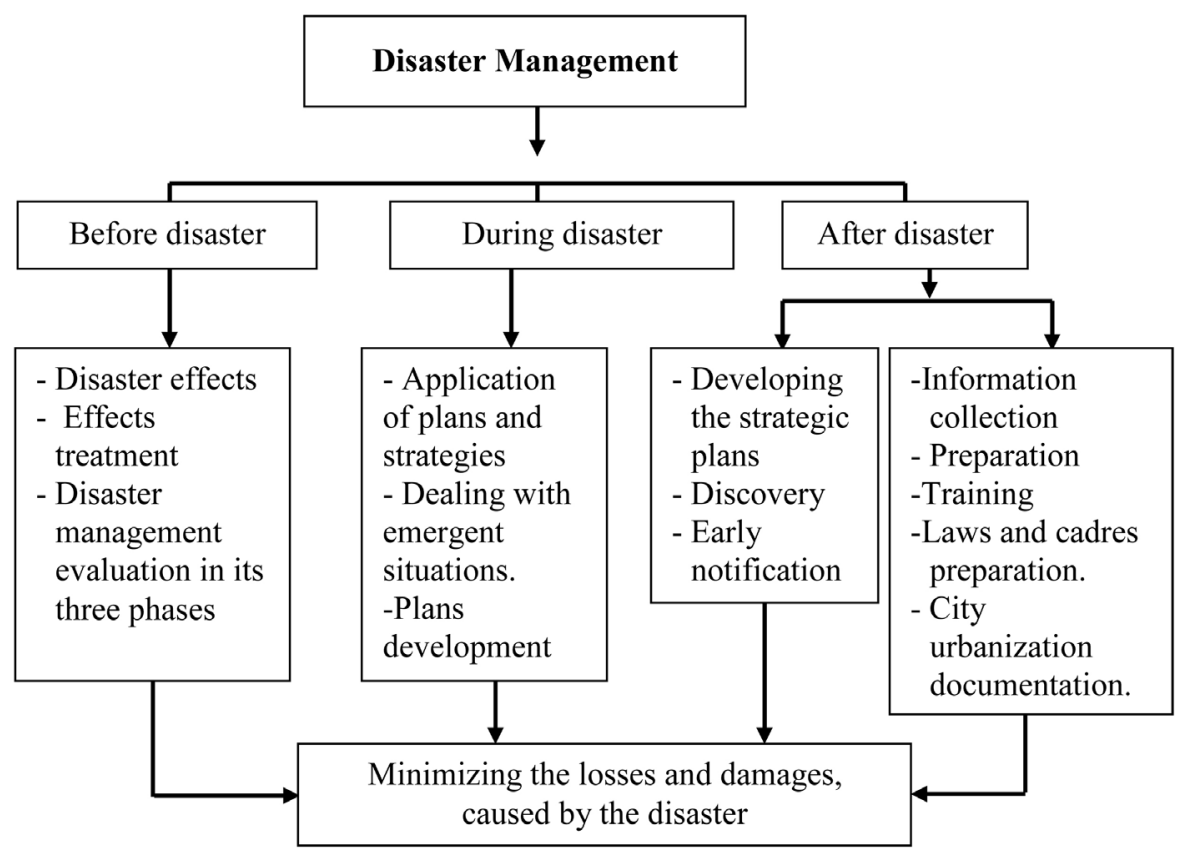

Figure 11. The proposed management approach for the earthquake disasters. 
along with the method of notification and direction as well as development of operational plans upon the occurrence of disaster and training on these plans shall be gathered.

Development of the training plan on several axes which are:

1) Action seismic maps of the Kingdom of Saudi Arabia Private General of the Arab region and the development of codes and laws of the buildings.

2) Modeling the city through the GIS for indicating the points of danger and strength in the city along with the traffic axes as well as the method of accessing the most subject able areas for risks as soon as possible.

3) Raising and documenting the archeological buildings and urbanization in the city along with the networks and methods accurately and in a manner, guaranteeing identification of the city features before and after the disaster via the survey raising and using the computer applications as well as the GIS, photos and video clips.

4) Developing the plans for coping with the effects of earthquakes, rubble removal, accommodation and evacuation as well as buildings maintenance and the analysis of defects leading to the collapse of buildings and readiness with an alternative plan in which effective mobilization for the energies and resources as well as well-management with the least losses and as soon as possible shall be available.

5) Developing a training plan for the entrusted work for transfer so as the tasks shall be distributed in advance. Therefore, such matter will help to the non-occurrence of confusion in the relief and rescue operations between the personnel as well as the conflicting decisions between the decision makers through either making experimental testing statement for the case of the occurrence of earthquake so as to train them upon the relief and evacuation operations as well as the number of cam [s and lifting the rubble.

6) The central governments and the policy makers shall work on establishing an independent and permanent authority for managing the disasters in the different developing regions along with allocating the fund and mechanisms for the provision of appropriate and fast financial credits domestically and internationally through the civil bodies organizations and authorities along with making use of the experts and technicians who are trained upon the disaster management operations and supplying them with the modern and appropriate equipment and devices.

Second: the phase of disaster occurrence:

1) Examination of facilities and receipt of communications for the effected buildings along with the formation of technical committees for preview.

2) Development of the evacuation priorities and accommodation of effected areas.

3) Lifting the rubble from the rundown buildings and the examination of infrastructure for status restoration as soon as possible.

4) Making the database for determining the size of losses and assessing the resulting damage for the buildings and infrastructure along with the number of effected persons, the size of necessary interim units and the restoration period.

5) Temporary facilities processing in accordance with the number of effected and the provision of necessary basic services. 
6) Request of aids and development of automatic mechanism for the restoration with the local efforts or external aids.

\section{Third: post-disaster phase:}

1) The completion of relief and protection works from diseases and epidemics.

2) The transfer of resulting wastes from demolished buildings.

3) Evaluation of the resulting damage from the earthquakes in quantity and quality.

4) Restoration and rehabilitation of devastated areas and follow-up of various projects.

5) Assessment of set out codes and laws and developing them according to the incident effects assessment.

6) Limitation of the points of weaknesses and shortcomings in the prior plans for avoiding and treating them.

\section{Results}

1) Earthquakes are the most natural disasters causing losses in the world and in the Arab nations.

2) The main reason for the occurrence of earthquakes is the movements of formative plats. There are other reasons for the occurrence of earthquakes which are unknown.

3) All the world regions are subjected to earthquakes of different scales.

4) The earthquakes cannot be fully predicted.

5) Identification of the disaster, characteristics and causes is important for the efficiency of its management.

6) The disaster management plays a significant role in reducing the various losses in a manner reaching about $70 \%$ in accordance with the real studies and experiences.

\section{Recommendations}

1) The construction of a centralized body for disaster management as a unique authority in the Arab League. It consists of the related governmental Ministries, and representatives of the main Arab relative organizations.

2) Directing the research to the enrichment of educational curricula and studies for disaster management.

3) The introduction of appropriate codes and laws for reducing the earthquakes risks in all fields.

4) Making contour models and enormous information for the earthquake regions in the Arab cities using GIS (pre-disaster preview).

5) To gain experiences from developed countries in earthquake disasters management. Training and simulation of disasters are among the interesting subjects.

6) Documenting and supporting historical buildings and classifying them on maps through GIS.

7) Participating in competent related international organizations.

8) Participating in teams of various relief operations around the world to increase friction, training and efficiency. 


\section{References}

[1] The Ministry of Defense, Cairo (1991) Crisis Management and Negotiation, Strategic Reference. The Ministry of Defense, Cairo.

[2] Fritz Charles, E. (1961) Disaster. In: Merton, R.K. and Nis-bet, R.A., Eds., Contemporary Social Problems, Harcourt, New York, 655.

[3] De Greene, K.B. (1982) The Adaptive Organization: Anticipation and Management of Crisis. Wiley \& Sons, New York, 183.

[4] International Civil Defence Organization (ICDO) Website (2016). http://www.icdo.org/en/

[5] Perry, R.W. and Nigg, J.M. (1985) Emergency Management Strategies for Communicating Hazard Information. Public Administration Review, 45, 12-11.

https:/doi.org/10.2307/3135000

[6] Nabarawy, A.M. (1995) Disasters, Floods. Unpublished Ph.D. Thesis, Ain Shams, Cairo, 8.

[7] Nelson, S.A. (2015) Earthquakes and the Earth's Interior. Physical Geology, Tulane University. http://www.tulane.edu/ sanelson/eens1110/earthint.htm

[8] Ailosh, M.N. (1996) The Basics of Earthquakes and Earthquake Engineering. Prentice-Hall International.

[9] Earthquake Commission, The Egyptian Syndicate of Engineers (1992) Manual Guide. Earthquake Commission, The Egyptian Syndicate of Engineers, Cairo.

[10] USGS Homepage (2016). https://earthquake.usgs.gov/earthquakes/world/world deaths.php

[11] Emirate of Madinah, Ministry of the Interior, Kingdom of Saudi Arabia (2015). http://www.imaratalmadinah.gov.sa/ar-SA/MedinaRegion/centers/Pages/ais.aspx

[12] General Presidency for Youth Welfare Website (2016). http://www.saudinf.com/main/c6y.htm

[13] Google Maps Website (2015). https://www.google.com.sa/maps/@24.266906,45.0983499,5z 
Submit or recommend next manuscript to SCIRP and we will provide best service for you:

Accepting pre-submission inquiries through Email, Facebook, LinkedIn, Twitter, etc.

A wide selection of journals (inclusive of 9 subjects, more than 200 journals)

Providing 24-hour high-quality service

User-friendly online submission system

Fair and swift peer-review system

Efficient typesetting and proofreading procedure

Display of the result of downloads and visits, as well as the number of cited articles

Maximum dissemination of your research work

Submit your manuscript at: http://papersubmission.scirp.org/

Or contact ojer@scirp.org 